\title{
Analysis on Influence Factors of Roadway Instability in High-Stress, Steeply Inclined Extra-Thick Coal Seam
}

\author{
Hai Rong $\mathbb{D}^{1,2}$ Liting Pan, ${ }^{1,}$ Xiaoyan Li, ${ }^{2,3}$ Ming Wang, ${ }^{2,3}$ Zeliang Qu, ${ }^{2,3}$ Mengsheng Lu, ${ }^{2,3}$ \\ and Kaipeng Guo ${ }^{1,4}$ \\ ${ }^{1}$ College of Mining, Liaoning Technical University, Fuxin, Liaoning Province, China \\ ${ }^{2}$ Engineering Laboratory of Deep Mine Rockburst Disaster Assessment, Jinan, Shandong Province, China \\ ${ }^{3}$ Shandong Province Research Institute of Coal Geology Planning and Exploration, Jinan, Shandong Province, China \\ ${ }^{4}$ State Key Laboratory of Mining Disaster Prevention and Control Co-Founded by Shandong \\ Province and the Ministry of Science and Technology, Shandong University of Science and Technology, Qingdao, China \\ Correspondence should be addressed to Hai Rong; ronghai1988@163.com
}

Received 8 April 2021; Accepted 18 August 2021; Published 13 September 2021

Academic Editor: Emanuele Brunesi

Copyright (c) 2021 Hai Rong et al. This is an open access article distributed under the Creative Commons Attribution License, which permits unrestricted use, distribution, and reproduction in any medium, provided the original work is properly cited.

\begin{abstract}
In order to solve the problem of roadway support safety in coal mining under high stress conditions and to improve safe and efficient production in coal mines, the control countermeasures of the surrounding rock stability and the optimization scheme of support are put forward and the model and numerical simulation of roadway bolt support system are established. Based on bolt support theory and instability mechanism of the coal rock dynamic system, this paper puts forward the evaluation of support effect and the optimization parameters of bolt support, and the scheme of mine pressure monitoring and the corresponding support optimization system are established. The roof fall accident and the bolt and cable of support have been broken in the Wudong coal mine, the phenomenon of bolt pulling out in the roadway. The causes of roof fall are analyzed and the solutions are put forth, judging the influence of different factors on roadway support. In view of the roof fall accident in the North Lane of the east wing of the +575 level 43 \#coal seam in the north mining area of the Wudong coal mine, the cause analysis and support suggestions are made. And, according to the performance of the bolting material and anchoring agent, the laboratory theoretical research was carried out. Through the experiment, it is concluded that the FRP bolt with a diameter not less than $27 \mathrm{~mm}$ is the first choice for the side support of the working face in the mining roadway, then ribbed steel bolt with a diameter not less than $20 \mathrm{~mm}$ for the nonworking face, and the length of the anchor rod not less than the range of the loose circle. Therefore, full-length anchoring should be carried out in roadway support, the anchorage length of the anchor cable should be increased, and the integrity of the roof should be improved, so as to reduce the amount of roadway roof separation and improve the support effect.
\end{abstract}

\section{Introduction}

Because of the different geological dynamic environment, the stress distribution characteristics and energy accumulation degree of coal bodies in different areas in the mining field are different; therefore, there are stress rising areas and coal rock mass areas with high degree of energy accumulation [1]. Under the influence of mining engineering activities, it will cause a redistribution of stress, forming a stress rising area, causing deformation of coal and rock mass and destruction, even leading to the release of energy. It leads to roadway instability and roof fall accidents, leading to rock bursts. Aiming to identify the reasons of roadway instability and deformation and supporting technology, Tan et al. [2] proposed two new indexes, namely, impact energy velocity index of coal rock combination and impact energy velocity index of unloading confining pressure. The evaluation system of coal rock burst tendency is established according to the types of rock burst, and the synchronous integration technology of drilling construction and early warning is developed aiming at the problem of rock burst monitoring and prevention in deep mining of coal mines. 
Pan et al. [3] based on the dynamic response of the surrounding rock and support of roadway established the mechanical model of "stress surrounding rock support." It is proposed that the support of the roadway against the impact of ground pressure should be from the static dynamic angle, the starting stress condition of rock burst under roadway support is that the far-field stress is greater than the critical stress, and the energy condition of stopping is that the energy absorbed by the surrounding rock and the energy absorbed by support is greater than that of the far field. Dou et al. [4] studied the energy and stress conditions of rock burst induced by the superposition of dynamic load and static load, and the principle of rock burst induced by superposition of dynamic and static loads is put forward. Jiang et al. [5] studied the mechanism and law of rock burst in coal mine, which are deformation and failure law and mining stress distribution of the deep intermittent coal body, spatiotemporal evolution of energy field. Hou et al. [6] put forward the strength strengthening theory of the surrounding rock. It is considered that bolt support can improve the mechanical parameters and properties of rock mass in anchorage zone, and then improve the bearing capacity of the surrounding rock; at the same time, the bolt and the rock mass in the anchorage zone form a bearing structure, jointly maintaining the stability of roadway. Dong et al. [7] put forward the theory of the surrounding rock loose zone. It is considered that after roadway excavation, the loose circle of the surrounding rock exists in the surrounding rock, and the main load of support is the interaction between the deformation generated in the formation of loose circle and the support body. According to the thickness of loose circle, the support mechanism and the corresponding support parameters are determined. Ran et al. [8] determined the combined support form of "front beam + bolt + anchor cable + metal mesh" in rectangular roadway, based on the theory of the surrounding rock loose zone. Pan [9] believed that the principle of rock burst initiation is that elastic brittle single structure breaks through material strength limit, material instability, as a result of the dynamic instability of engineering structure. Liu et al. [10] using the orthogonal numerical simulation method, the variation laws of plastic zone volume, roof and floor movement and two-side convergence under different bolt lengths, preloads, and top angle bolt installation angles are systematically studied, the multi-index orthogonal design matrix analysis method of roadway bolt support is proposed, the supporting scheme of supporting engineering is optimized, and the field industrial test is carried out, Finally, the multifactor analysis of the roadway support and multi-index evaluation of the support effect are realized. Zuo et al. [11] considered that the roadway should be supported from the whole space, and the theory of equal strength beam support in deep coal mine roadway is put forward; it is considered that according to the different damage degree of surrounding rock of the roadway, support with different length bolts should be provided, so that the surrounding rock of the roadway is evenly stressed. Zhang et al. [12] combined fuzzy mathematics with extenics, and the parameters of roadway support are optimized. Thus, the problem of roadway support is effectively solved. Cai et al. [13] analyzed the mineral composition by XRD and SEM, and researched the physical and mechanical properties of the weakly cemented soft rock. Secondly, using the research methods of field investigation and physical simulation experiment, this paper studies the roadway failure and deformation mechanism and control technology and puts forward the coupling control technology of the "inverted trapezoidal" anchor mesh cable beam support structure with high strength and high preload + straight wall cutting arch roadway section + full section shotcrete. Li [14] studied the instability mechanism of weakly bonded roof systematically, and the long anchor cable is proposed as the leading factor, that is, multilevel roof control technology involving long anchor and short anchor cables. Meng et al. [15] adopted the optimization of roadway cross section shape and double-layer anchorage balanced arch structure to solve the problem of roadway surrounding rock stability control in extremely weak stratum. Wang et al. [16] taking the weak cemented soft rock roadway of the Yi li No. 1 mine as the research object, based on the analysis of deformation and failure of surrounding rock of the roadway, and optimization of support parameters by numerical simulation, put forward the scheme of anchor mesh cable coupling support. Huang [17] used physical simulation and FLAC 3D numerical calculation; combining with the theory of self-stable balance ring, the optimal section of straight wall with arc and reverse arch is determined, supported by "anchor cable + steel ladder + metal mesh grouting." Yang et al. [18] adopted a combination of mechanical analysis and numerical simulation for proposing a supporting system with the core of "high strength anchor net, beam and cable + shotcrete sealing + floor anchor grouting". Sun [19] using artificial intelligence, indoor experiment, theoretical analysis, engineering investigation proposed the research method of combining numerical calculation and field tests. The rheological model of coal is established, the rheological parameters of roadway coal are inversed, and the rheological mechanism of roadway is revealed; the control measures of grouting by rotary injection to strengthen the loose coal body are put forward, and it makes an important contribution to the research and treatment of loose coal roadway rheology. Sun [20] established the fracture mechanics model of overburden; using mts- 815 rock mechanics test system and fatigue damage test of sandstone under cyclic loading by acoustic emission system, the disaster mechanism of overburden fault is studied; deformation and failure law of surrounding rock in deep roadway, mechanical behavior of rock under cyclic loading, energy dissipation and fatigue damage characteristics, and the influence factors and deformation mechanism of surrounding rock deformation under dynamic disturbance are analyzed, and the control scheme of surrounding rock deformation is put forward. Fan et al. [21] put forward the combined support technology of "bolt mesh shotcreting active support $+36 \mathrm{U}$ steel support + full face bolt grouting" based on X-ray diffraction experiment, scanning electron microscope, physical test, and field monitoring of rock mechanics; the field monitoring results show that the improved support scheme can effectively control the deformation of surrounding rock and the 
expansion of plastic zone, and ensure the long-term stability and safety of the roadway. Chen [22] established the mechanical model of surrounding rock stress and deformation of straight wall arch roadway in steep seam, combined with the theory of complex variable and conformal transformation and influence of mining intensity and dip angle; the analytical solutions of stress and deformation of surrounding rock under different mining intensities and dip angle are obtained by genetic algorithm, and the influence of mining intensity and dip angle on the instability mode of large dip angle roadway is revealed from the perspective of mechanics. Su et al. [23] used the physical similarity simulation test method, the deformation and failure characteristics and stress evolution law of layered rock roadway with different support methods are studied, and the arching characteristics of layered rock roadway are analyzed from the perspective of pressure arch. Chu et al. [24] further studied the distribution of stress and strain before and after roadway support in the contact zone between ore and rock by numerical simulation. Through on-site deformation monitoring data and physical and mechanical parameters of ore and rock, the tensile failure volume is calculated from the plastic zone. Comparative analysis of shear failure volume and total volume of bolt support, shot crete support, application effect of combined bolting, and shotcreting support is performed. Finally, the paper puts forward the partition support method for the mine rock contact zone roadway. Yu et al. [25] studied the asymmetric deformation and failure of Soft Rock Roadway after excavation, and the asymmetric control technology of strengthening support for weak structure is put forward. Wang et al. [26] systematically analyzed the variation characteristics of stress, displacement, and plastic zone of the surrounding rock before and after deep soft rock roadway support are simulated. Guo and Song [27] through field measurement, mineral composition and water quality analysis, surrounding rock disintegration and mechanical properties test, and numerical simulation studied the instability characteristics and mechanism of the water drenching roof roadway in the transportation roadway. Thus, the influencing factors of roadway instability under the water drenching roof in the gob with accumulated water are obtained. Yao et al. [28] explored the roof instability mechanism of water-rich coal seam from micro and macro aspects: due to roof cracks caused by disturbance of roadway excavation, the hydraulic connection between the immediate top aquifer and the basic top aquifer is formed. Because silty mudstone is composed of hydrophilic minerals and the microstructure fracture is developed, it is easy to expand after absorbing water; under the action of threedimensional stress, disintegration damage occurs. At the same time, the bearing capacity of the support is weakened, resulting in instability of the roadway roof. Zheng et al. [29] analyzed the mechanism of buckling of layered floor by mechanical theory, by establishing the mechanical model of the layered floor of the roadway with equal spacing bottom anchor; the mechanical criterion of heave instability of layered floor is established, with the help of the proposed mechanical criterion, and the stability of the floor is determined and evaluated, The rock strata which are the first to disintegrate leading to the failure of the support system are obtained. Li et al. [30] aiming at the problem of surrounding rock deformation and instability of thin-layered soft floor roadway, the buckling instability mechanism and control technology of thin-layered soft floor roadway are studied in detail by integrating theoretical analysis, mechanical calculation, numerical simulation, underground test, and field measurement methods. According to Lu and Yao [31], the bedded rock mass in the floor is regarded as a transversely isotropic continuum. According to the overburden load distribution characteristics of coal seam, the analytical solution of floor stress at any point after coal mining is derived, and the influence of the anisotropy of the deformation parameters on the stress distribution is analyzed. Xu et al. [32] discussed the fracture instability mechanism and control technology of narrow coal pillar through the combination of theoretical analysis, numerical simulation, and field measurement and put forward the support scheme of fully mechanized top coal caving goaf roadway of the "high-strength bolt support + roof anchor cable channel steel composite structure + coal pillar side anchor cable reinforcement" and carried out field application. Following discussion on the failure mechanism of narrow coal pillar and its control technology, the supporting scheme of "high strength bolt support + roof anchor cable channel steel composite structure + coal pillar side anchor cable reinforcement" is put forward and applied on-site. Zhang et al. [33] analyzed the dynamic process of structural damage of roadway roof caused by the key block breaking and rotating process under the condition of gob side entry driving in mining face, and put forward the pre-stressed combined support technology, and carried out the field engineering practice. Hao et al. [34] used field measurement, theoretical analysis, and numerical simulation, and the instability mechanism and main influencing factors of mining roadway are discussed. According to the physical and mechanical properties and stress characteristics of surrounding rock of test roadway, the targeted solutions are put forward. Vazaios et al. forecasted the hazard of rockburst and coal and gas outburst in roadway at different mining depths based on the finite-discrete element method and other methods [35, 36].

About roadway support, the research mainly focuses on the occurrence conditions of near horizontal and gently inclined coal seams, and there are few domestic reports on the causes of roadway instability and deformation and supporting technology under the condition of high stress and steep inclination. The north mining area of the Wudong coal mine in Shenhua Xinjiang is a high-stress steeply inclined coal seam. The extension direction of mining roadway is nearly perpendicular to the direction of maximum principal stress, and it is strongly compressed by in situ stress. It has an important influence on the stability of roadway; occasionally, roof fall accidents of different degrees occur, for example:

On April 17, 2017, a roof fall accident occurred at the south of the top of the North roadway of the east wing of +575 horizontal 43\# coal seam in the north mining area of Wudong mine. The roadway was filled with coal and rock slag, which had a serious impact on the safety production of 
the mine.. In this paper, the geological dynamic conditions are analyzed, along with fault structure division, on-site monitoring, laboratory experiment, and numerical simulation. In this paper, the causes of roadway instability and roof fall in Wudong high-stress steeply inclined extra-thick coal seam are analyzed in detail and some suggestions are given. It provides the basis and direction for further optimization of roadway support in the Wudong coal mine, and technical support and security for safe and efficient production at the mine. It provides important support for the technical progress and sustainable development of mines with similar conditions.

\section{Analysis of Support Problems in the Wudong Mine Field}

2.1. General Situation of Mine. The Wudong coal mine is located to the east of Zhungeer coalfield, northwest limb of the Bogda mountain anticline, north of yaomengshan Lucaogou reverse fault. The Wudong coal mine is located in the Bogda mountain fault zone system, high in the south and low in the north. The maximum elevation is $934 \mathrm{~m}$, minimum is $739.20 \mathrm{~m}$, and the maximum relative height difference is $130 \mathrm{~m}$. Generally, the height difference is $60 \mathrm{~m}$. It lies between the north foot of Bogda mountain and the southeast edge of Junggar basin. Most of the structures in the area are NE trending, and the Mesozoic strata constitute asymmetric linear tight folds. The Wudong minefield belongs to the piedmont hilly belt at the north foot of Bogda; small valleys crisscross, the large-scale gullies are mainly north-south, there is little outcrop in the area, and most of them are covered by Quaternary loess and sandy loam. Due to the long history of coal mining in the working area, most of the surface collapse pits in the goaf are developed; according to rough statistics, there is one collapse per $100 \mathrm{~m}$ on average, every $200 \mathrm{~m}$ of the mine shaft. The Wudong mining area is located in the southeast of Zhunnan coalfield, it belongs to piedmont secondary tectonic unit, it is distributed in the northeast direction, and it is basically consistent with the distribution direction of the Tianshan latitudinal structural system. The minefield is located in the north and south wings of the Badaowan syncline, a secondary fold in the Piedmont depression of Urumqi. Large structures in the mining area include qidaowan anticline, Badaowan syncline, wanyaogou thrust fault, and baiyangnangou anticline.

The south mining area of the Wudong coal mine is located in the south wing of the Badaowan syncline, and it comprises 32 coal-bearing beds. The main coal seam is $\mathrm{B} 1+2$ and $\mathrm{B} 3+6$ coal. The maximum thickness of $\mathrm{B} 1+2$ coal seam is $39.45 \mathrm{~m}$, minimum thickness is $31.83 \mathrm{~m}$, and the average thickness is $37.45 \mathrm{~m}$. The maximum thickness of $\mathrm{B} 3+6$ coal seam is $52.3 \mathrm{~m}$, minimum thickness is $85.39 \mathrm{~m}$, and the average thickness is $48.87 \mathrm{~m}$. The dip angle of coal seam is 87 degrees, and it belongs to steep coal seam. The two groups of coal are separated by a rock wall, the dyke gradually thinned from west to East, and the variation range is between $53 \mathrm{~m}$ and $110 \mathrm{~m}$. The main minable coal seams in the north mining area are coal seams 43 and 45 . the pseudo roof of the coal seam is carbonaceous mudstone or mudstone, and the thickness is about $1 \mathrm{~m} \sim 3 \mathrm{~m}$. The direct roof is siltstone or sandy mudstone; the main roof is siltstone, fine sandstone, or medium sandstone, the pseudo floor of the coal seam floor is carbonaceous mudstone or mudstone; and the direct bottom is siltstone. The occurrence characteristics of coal seams in the Wudong coal mine are shown in Figure 1. Because of this natural factor, roadway instability deformation and roof fall accidents often occur in the process of mining in the north mining area.

2.2. Factors of Tectonic Stress Field in the Minefield. Judging from the rate of crustal activity, the criteria for judging strong active faults are: since the middle late Pleistocene, it is active and strong in Holocene, the average fault activity rate is $v>1 \mathrm{~mm} / \mathrm{a}$, and the historical earthquake magnitude is $M \geq 7$. The criteria for moderately judging active faults are as follows: it has been active since the middle late Pleistocene, and the Holocene activity is relatively strong, $0.1 \mathrm{~mm} / a \leq v \leq 1 \mathrm{~mm} / a, 5 \leq M<7$. The criteria for judging weak active faults are: It has been active since the middle late Pleistocene, and the Holocene activity is relatively strong, when $V<0.1 \mathrm{~mm} / \mathrm{a}, M<5$ [37]. The northern edge of the Bogda fault is in a strong compression state, as shown in Figure 2. The study area is a thrust nappe structure, and its basic structure is roughly divided into the root thrust fault zone, central detachment layer, and front compression uplift zone. From the rate of crustal activity in the Tianshan area, the northern edge of the Bogda fault in the Wudong minefield is in a strong compression state. Under the influence of this dynamic state, a large amount of elastic deformation energy is accumulated in the region. The direction of maximum principal stress is NNW and NW, the difference between the maximum principal stress and the minimum principal stress is large, the horizontal force gradient is large, and the effect of extrusion stress is obvious. The number of earthquakes in the Wudong mine field is increasing with every passing year; it shows that the geological dynamic conditions are more and more active, and the energy of rock mass in the mining area also increases with every passing year.

The Wudong minefield inherits the action characteristics of the regional stress field. In situ stress is dominated by horizontal compressive stress, the maximum principal stress direction is $\mathrm{N} 27.8^{\circ} \mathrm{W}$. The mining roadway in the Wudong coal mine is mainly arranged along the strike direction of the coal seam; the strike direction of the roadway is $\mathrm{N} 59^{\circ} \mathrm{E}$, and the angle between the maximum principal stress and the strike of roadway is 94 degrees, near vertical. As shown in Figure 3 , the mining roadway in the Wudong coal mine is strongly affected by in situ stress. It has an important influence on the stability of roadway support.

\subsection{Structural Fracture Factors in the Minefield.} Application of geo dynamic zoning method to grade I-V fault structure division in the Wudong mine field and the geological dynamic conditions are analyzed, faults are determined by geological dynamic zoning, and the 


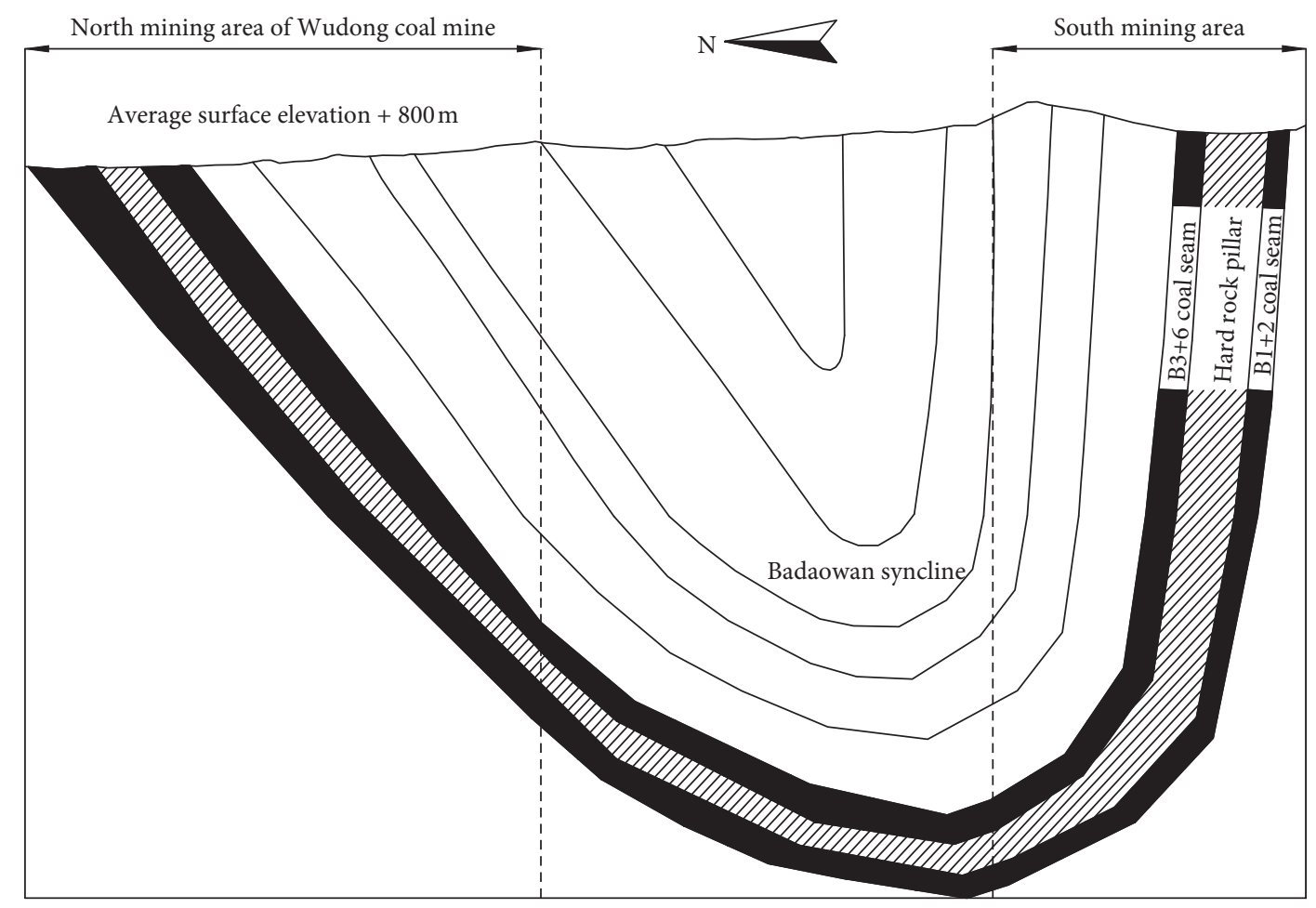

Figure 1: Geological profile of the Wudong coal mine.

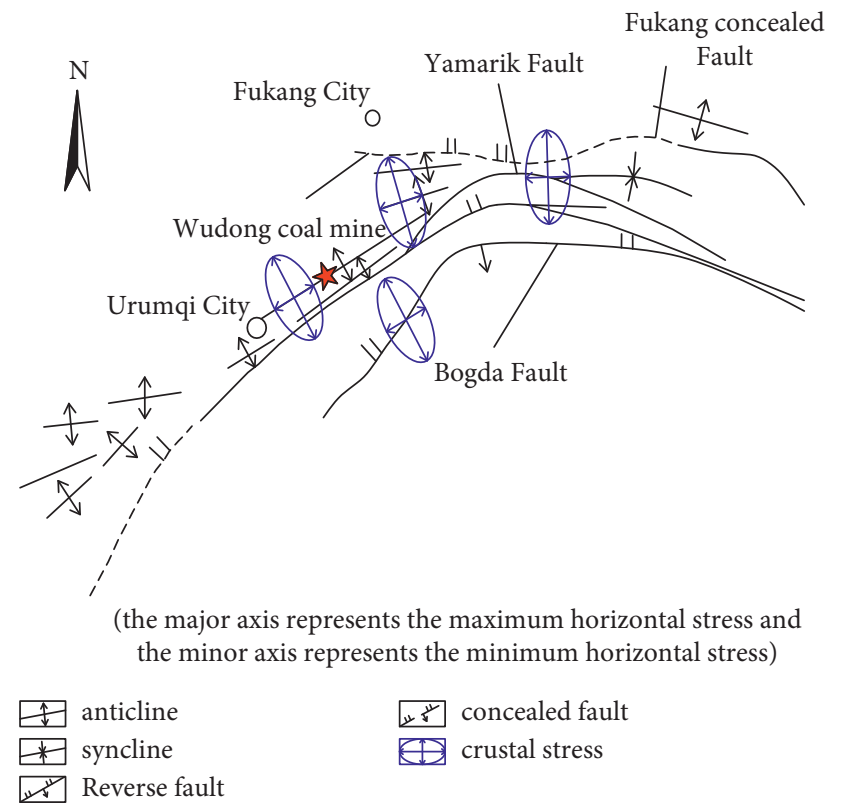

Figure 2: Structural stress distribution of the bogda fault zone system.

characteristics of regional geological dynamic state are revealed. The activity of fracture means the change of dynamic system so as to cause the accumulation and increase of energy. The movement of fault structure makes the stress structure of coal and rock mass redistributed, and the stress and energy in the crust are released. Take grade $\mathrm{V}$ fracture diagram as an example; in this paper, the roof fall area of the North roadway and roadway in the east wing of the +575 level 43 \# coal seam in the north mining area of the Wudong coal mine is combined with the V-level fault map, as shown in Figure 4.

As can be seen from Figure 5, the roof fall area is affected by V-5 active fault. It occurs nearly $180 \mathrm{~m}$ away from V-5 active fault, as shown in Figure 5. The activity of V-5 active fault provides power source and energy basis for coal and rock mass in the roof fall area. Besides, there are intersection points between the North Lane in the east wing of coal seam +575 and V-5 fault and iv-3 fault, respectively. The intersection points are $434 \mathrm{~m}$ and $2278 \mathrm{~m}$ in the North Lane of the east wing of the +575 coal seam. Therefore, there is a risk of roof fall at the intersection.

2.4. Experimental Study on Stress Analysis of the Bolt Body and Anchoring Agent. Tensile strength of bolt is one of the most important indexes of bolt mechanical properties. At present, the anchor material used in the Wudong coal mine is hbr335. For this reason, we carried out the pull-out experiment of threaded bolt in the Wudong coal mine. The phenomenon of bolt sliding appeared in the experiment, and as a result, the drawing force has a small change. The experimental process is shown in Figure 6. The experimental results are shown in Table 1.

It can be seen from the experimental results that mechanical parameters of rebar bolt body in the Wudong coal mine, namely, pull-out force of $189 \mathrm{kN}$, tensile strength of $601 \mathrm{MPa}$, and elongation of rod body by $20.61 \%$, meet the support material standard of the Wudong coal mine. Therefore, the material and property of bolt body in the Wudong coal mine is not the cause of roof fall of supporting roadway in the Wudong coal mine. 


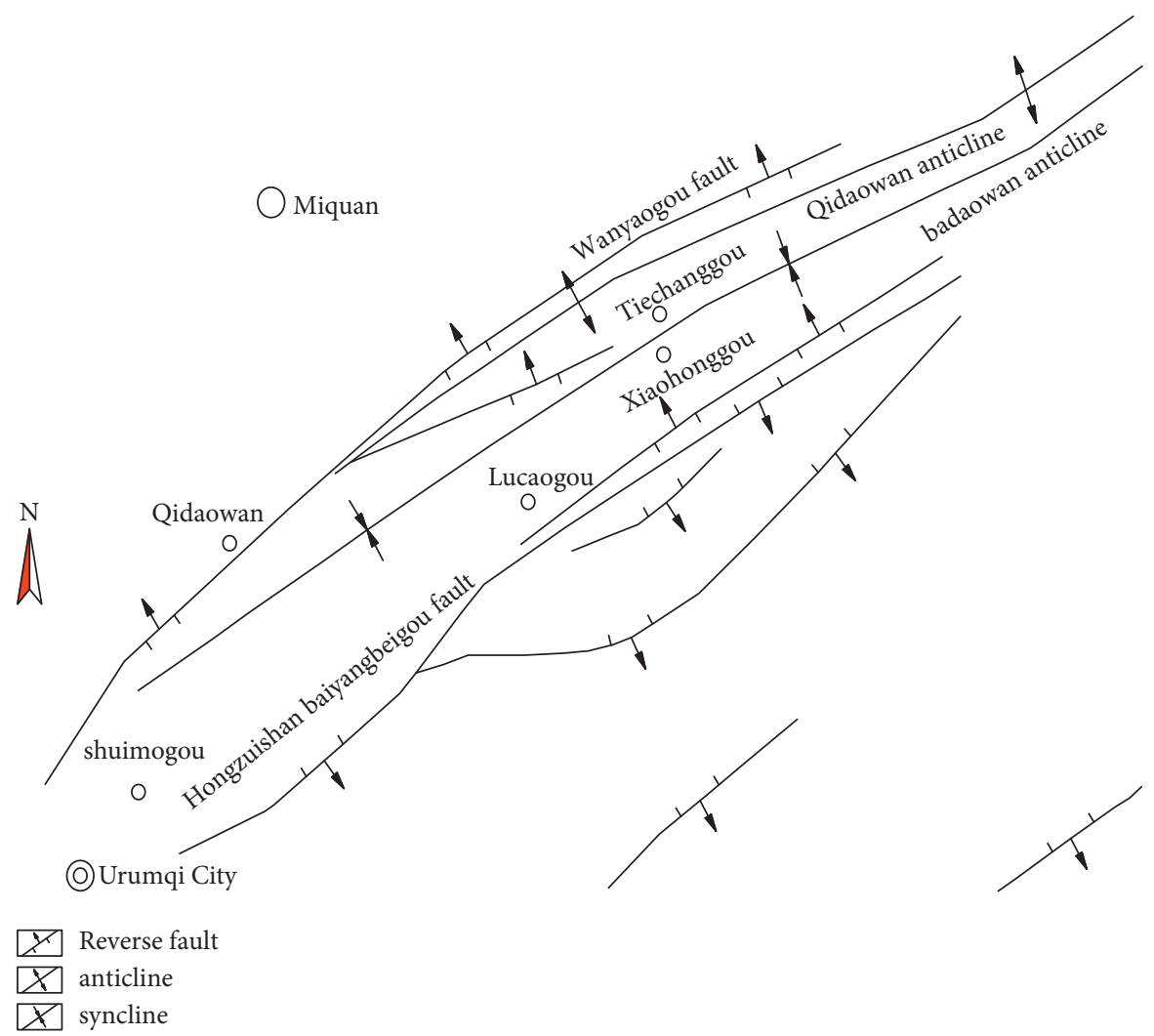

Figure 3: Characteristics of in situ stress in the Wudong minefield.

The length of anchor also has a certain influence on the supporting effect, in order to master the bolt supporting effect of different bolt lengths. The anchorage performance of $1 \mathrm{~m} \times 1 \mathrm{~m} \times 1 \mathrm{~m}$ concrete blocks with $150 \mathrm{~mm}$ and $300 \mathrm{~mm}$ anchorage length was tested in the laboratory. During the experiment, $Z Y$ portable bolt drawing instrument and dial indicator were used to apply pressure and test bolt displacement, respectively. The experimental process is shown in Figure 7. Drawing force of screw steel bolt (anchorage $150 \mathrm{~mm}$ ) is shown in Figure 8. Drawing force of screw steel bolt (anchorage $300 \mathrm{~mm}$ ) is shown in Figure 9.

Summary of pull-out force of bolt with different anchorage lengths is shown in Table 2. On analyzing the experimental results, it is found that when the anchor length is $150 \mathrm{~mm}$, the pull-out force of the bolt can reach more than $60 \mathrm{kN}$; when the anchorage length is $300 \mathrm{~mm}$, the anchor force increased by $50 \%$, thereby increasing the length of bolt in roadway support. It is suggested that full-length anchorage should be used in roadway support. It can significantly improve the quality of bolt support.

The resin anchoring agent has excellent performance. It has the characteristics of "double fast and one high." "Double fast and one high" refers to fast strength growth, fast curing time (adjustable speed), and high strength. The mechanical parameters of anchoring agent used in the Wudong coal mine are tested. The results are shown in Table 3. In order to test its anchoring performance, a cylindrical specimen with a height diameter ratio of $2 \pm 0.2$ and a specification of $50 \mathrm{~mm}$ were made with a self-made mold and mine anchoring agent (MSCKa23-35) as the $50 \mathrm{~mm}$ long $\times 50 \mathrm{~mm}$ wide $\times 50 \mathrm{~mm}$ high cube specimens are used for uniaxial compression and shear tests, respectively. Cylindrical specimens with height diameter ratio of $2 \pm 0.2$ and Cube Specimens with size of $50 \mathrm{~mm} \times 50 \mathrm{~mm} \times 50 \mathrm{~mm}$ (length $\times$ width $\times$ height) were made for uniaxial compression and shear tests, respectively. The processes are shown in Figures 10 and 11, respectively.

According to the experimental results, the compressive strength of anchorage agent in the Wudong coal mine is consistent with the standard of more than $60 \mathrm{MPa}$ in the inspection requirements. So, the anchoring agent is not the main reason that affects the supporting effect of the Wudong coal mine.

\section{Monitoring Equipment and Scheme of the Experiment}

\subsection{Detection of the Roadway Surrounding Rock Structure}

3.1.1. Monitoring Equipment. YTJ20 type strata detection recorder is mainly used to monitor the +575 level 43 \# coal seam in the north mining area of the Wudong coal mine, as shown in Figure 12.

3.1.2. Monitoring Scheme and Result Analysis. Two test drillings are arranged in the North Lane of coal seam 43 in the north mining area of the Wudong coal mine: one for each roof, and one for each of the two sides of the tunnel. The results of field data acquisition with YTJ 20 type strata detection recorder show that: 


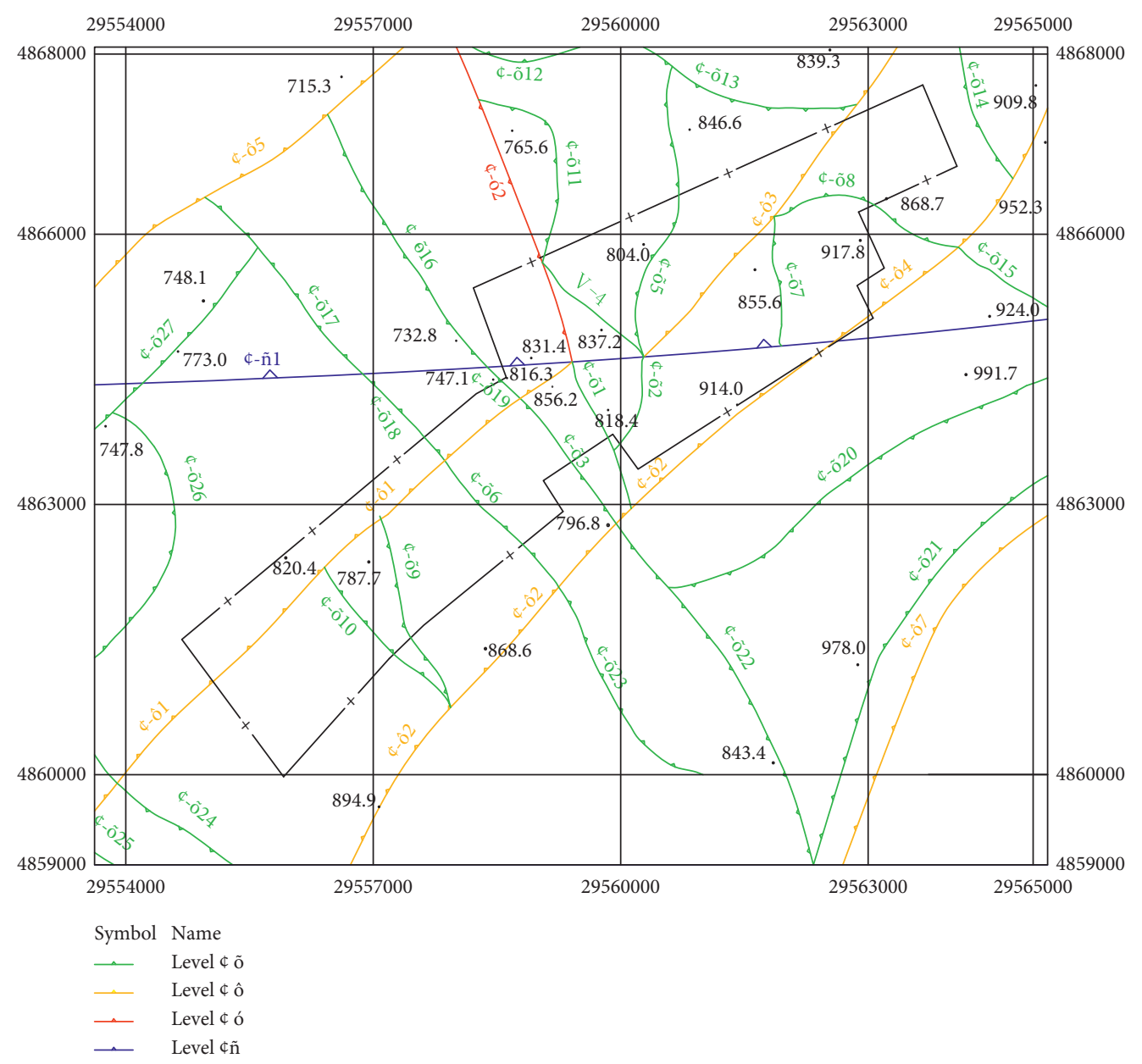

FIgURE 4: Grade V fault map of the Wudong minefield.

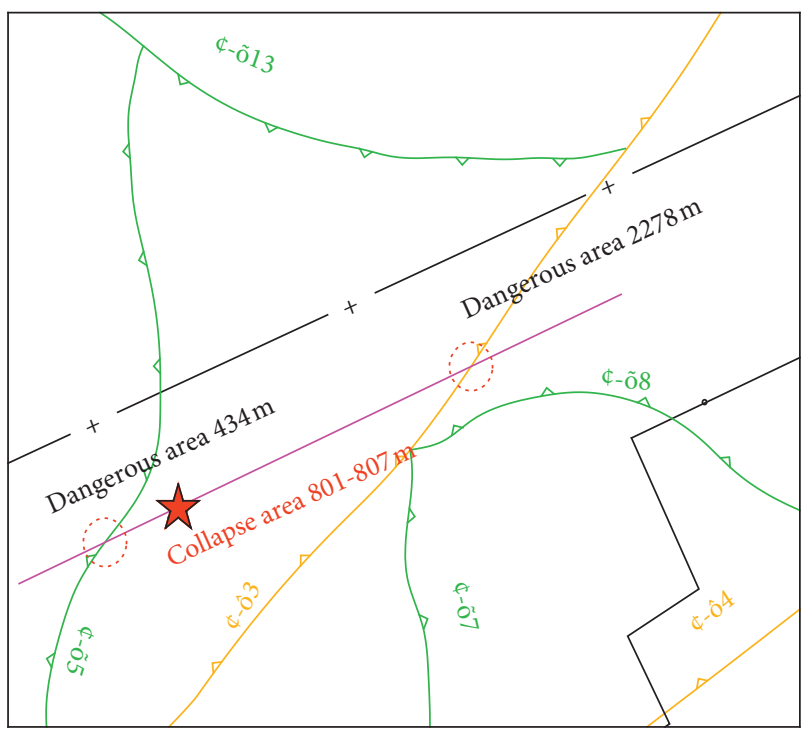

Figure 5: Relationship between roof fall area and fault location.

The surrounding rock structure of the 1 \# roadway at the test drilling site is relatively broken. There are fracture phenomena in different depths of coal wall. The fracture in parallel boreholes is more serious. As the drilling goes deeper, the fracture phenomenon improves. The fissures of the surrounding rock are relatively developed. There are cracks both in parallel drilling and $45^{\circ}$ drilling. The roof is relatively complete; there is no obvious breakage and separation in the roof drilling. As shown in Figure 13, the 2\# actual detection depth of the detection surface is $3.7 \mathrm{~m}-6.6 \mathrm{~m}$. The coal side is also relatively broken and the fracture development of the rock wall is not obvious relative to the 1 \# detection point, but there is a phenomenon of coal rock interbedding. The roof of the test drilling is also relatively complete, and there is no obvious breakage and separation in the roof drilling, as shown in Figure 14. During the detection of surrounding rock structure, the north mining area is in a stopping state. Therefore, it is not affected by mining.

Judging from the detection results, in the north mining area of the Wudong coal mine, the two sides of the North Lane in the +575 level 43 coal seam are relatively broken. Therefore, more attention should be paid to the detection of the two sides of the roadway. Select the appropriate support scheme in the broken area.

3.2. Test and Analysis on the Loose Zone of Roadway Surrounding Rock. Before roadway excavation. The rock mass is in a state of natural stress equilibrium, the natural 


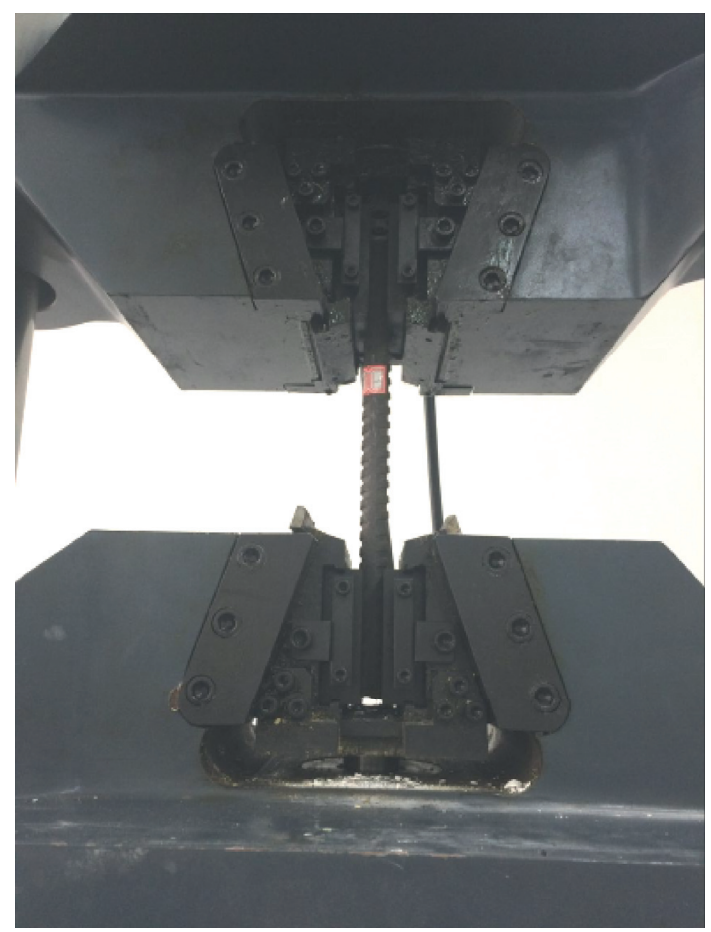

(a)

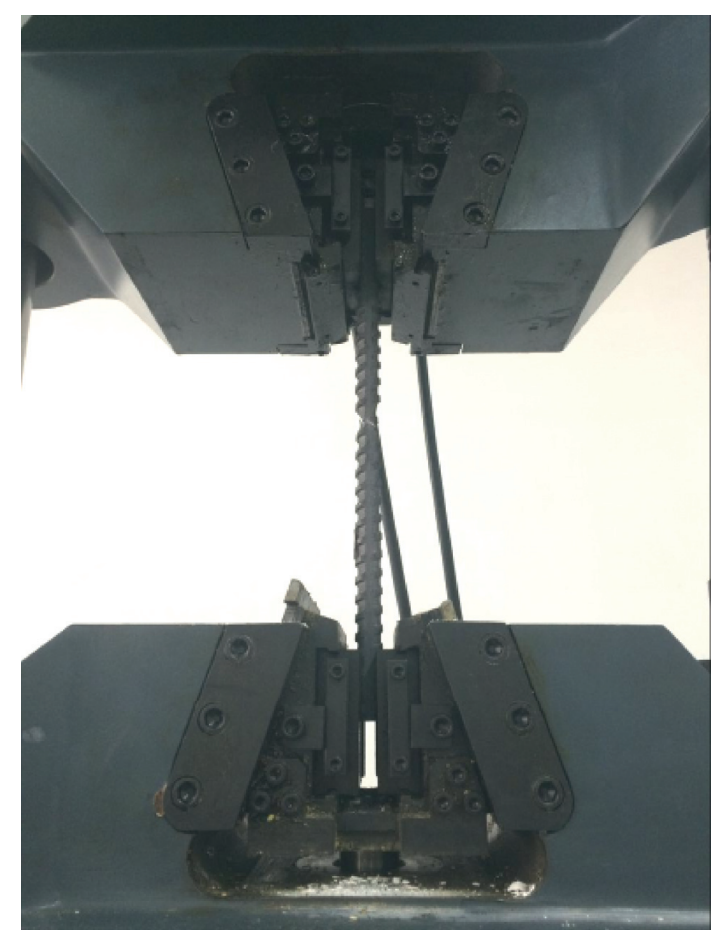

(b)

FIGURE 6: Drawing process of bolt body. (a) Rod body installation. (b) Broken rod. (c) Failure mode of the rod.

TABLE 1: Drawing test results of deformed steel bars.

\begin{tabular}{|c|c|c|c|c|c|c|c|}
\hline \multirow[b]{2}{*}{ Number } & \multirow[b]{2}{*}{$\begin{array}{l}\text { Original length of stretching } \\
\text { section }(\mathrm{mm})\end{array}$} & \multirow[b]{2}{*}{$\begin{array}{l}\text { Stretch length } \\
\qquad(\mathrm{mm})\end{array}$} & \multirow{2}{*}{$\begin{array}{l}\text { Rod diameter } \\
\qquad(\mathrm{mm})\end{array}$} & \multicolumn{2}{|c|}{ Elongation of rod (\%) } & \multicolumn{2}{|c|}{ Pull-out resistance $(\mathrm{kN})$} \\
\hline & & & & $\begin{array}{c}\text { Actual } \\
\text { measurement }\end{array}$ & $\begin{array}{l}\text { Mean } \\
\text { value }\end{array}$ & $\begin{array}{c}\text { Actual } \\
\text { measurement }\end{array}$ & $\begin{array}{l}\text { Mean } \\
\text { value }\end{array}$ \\
\hline $1 \#$ & 205.50 & 39.28 & 20.05 & 19.11 & & 188 & \\
\hline $2 \#$ & 203.20 & 42.40 & 20.10 & 20.86 & 20.61 & 185 & 189 \\
\hline $3 \#$ & 201.56 & 44.10 & 20.08 & 21.87 & & 194 & \\
\hline
\end{tabular}

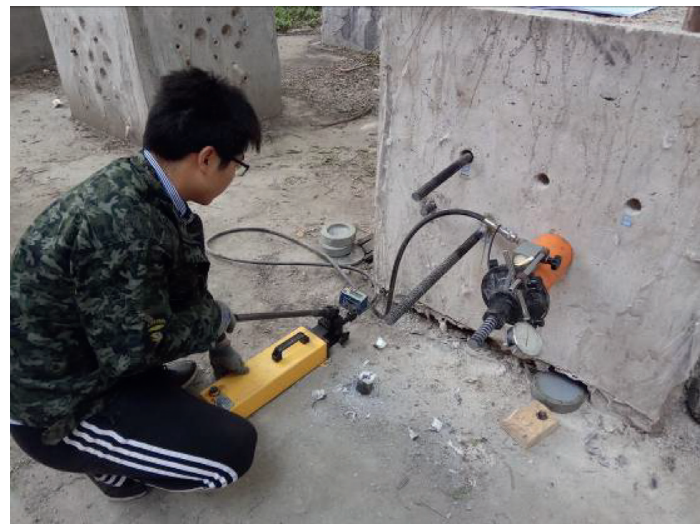

Figure 7: Pull-out test of different bolts.

stress is the original rock stress. After roadway excavation, the stress is redistributed to the surrounding rock of the roadway. There is a stress change area in the surrounding rock. Stress concentration occurs in this area. The stress concentration around the roadway is the most serious. When the stress exceeds the strength limit or yield limit of the surrounding rock mass, the rock mass around the roadway is destroyed first, or ruptures, and a certain range of loose area is formed around the roadway.

In this paper, the change of wave spectrum parameters, such as wave velocity, wave amplitude, wave form, and spectrum, is detected in the process of acoustic signal propagation in rock mass. Through these changes, we can indirectly understand the physical and mechanical properties and structural characteristics of rock mass media and the change of sound wave propagation velocity in rock mass, and the loose range of surrounding rock around roadway can also be obtained indirectly. Using BA-II ultrasonic rock crack detector to test the rock loose zone of +575 horizontal roadway in North Mining Area, three test positions were selected in the North roadway of coal seam 43, namely, in the heading roadway, which are $1340 \mathrm{~m}, 1370 \mathrm{~m}$, and $1400 \mathrm{~m}$, respectively. In order to ensure the reliability of the test, three boreholes were drilled in each place with spacing of $1.5 \mathrm{~m}$, as shown in Figure 15.

According to the field observation results, the anchoring end of the bolt in the roof fall area of the North Lane of the east wing of the +575 level 43 \# coal seam in the north 


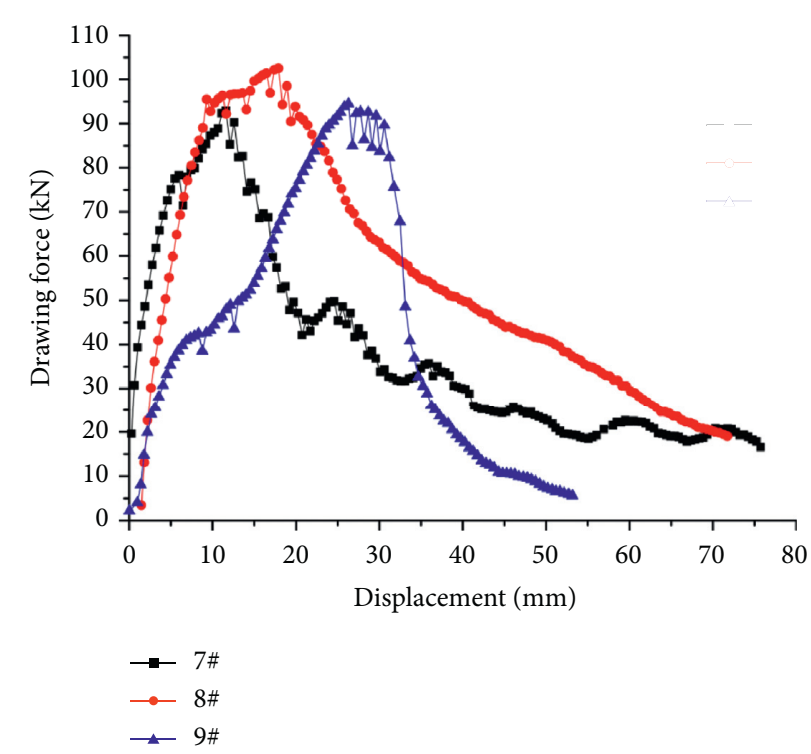

FIGURE 8: Drawing force of screw steel bolt (anchorage $150 \mathrm{~mm}$ ).

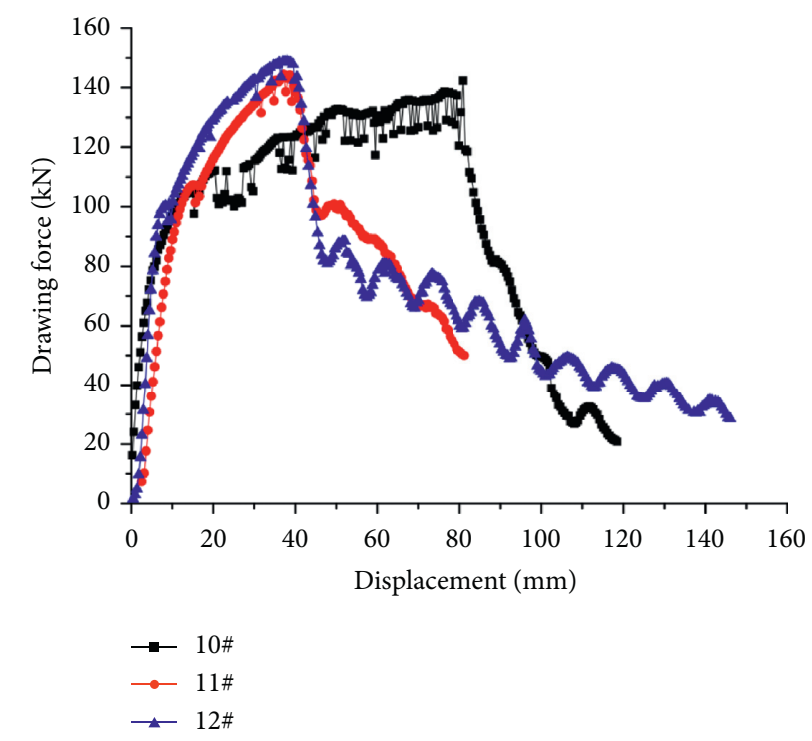

FIgURE 9: Drawing force of screw steel bolt (anchorage $300 \mathrm{~mm}$ ).

TABle 2: Summary of pull-out force of bolt with different anchorage lengths.

\begin{tabular}{lccccc}
\hline Type & Number & $\begin{array}{c}\text { Design anchorage } \\
\text { length }(\mathrm{mm})\end{array}$ & Actual anchorage length $(\mathrm{mm})$ & Rod diameter (mm) & Failure load (kN) \\
value $(\mathrm{kN})$
\end{tabular}

mining area of the Wudong coal mine is located at the coal rock joint. It is in the area of weak rock stratum. At present, the length of the bolt used in the Wudong coal mine is $2500 \mathrm{~mm}$. When the bolt is supporting, the exposed length of the anchor rod is $100 \mathrm{~mm}$. The length of anchoring into the surrounding rock is $700 \mathrm{~mm}$. If the $2500 \mathrm{~mm}$ long bolt meets the actual requirements, the thickness of the loose ring should be less than $1700 \mathrm{~mm}$, as shown in Figure 16. Test 
TABLE 3: Summary of mechanical parameters of anchoring agent used in the Wudong coal mine.

\begin{tabular}{lccccc}
\hline Type & $\begin{array}{c}\text { Compressive strength } \\
(\mathrm{MPa})\end{array}$ & $\begin{array}{c}\text { Elastic modulus } \\
(\mathrm{GPa})\end{array}$ & $\begin{array}{c}\text { Poisson's } \\
\text { ratio }\end{array}$ & $\begin{array}{c}\text { Cohesion } \\
(\mathrm{MPa})\end{array}$ & $\begin{array}{c}\text { Internal friction angle } \\
\left({ }^{\circ}\right)\end{array}$ \\
\hline $\begin{array}{l}\text { Anchoring agent (MSCKa23- } \\
35)\end{array}$ & 62.02 & 13.03 & 0.26 & 9.42 & 33.97 \\
\hline
\end{tabular}

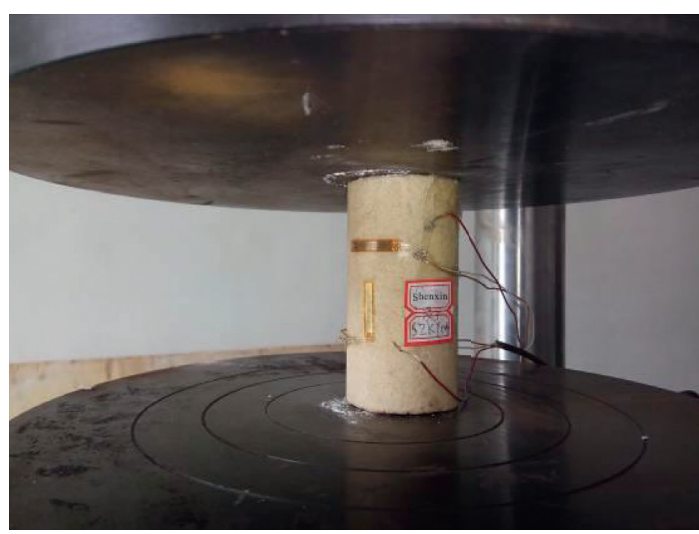

(a)

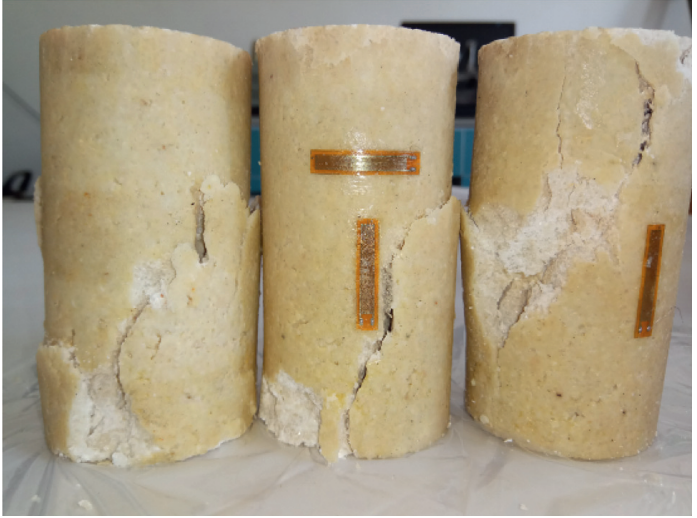

(b)

Figure 10: Process of uniaxial compression test and failure specimen. (a) Specimen installation. (b) Failure specimen.

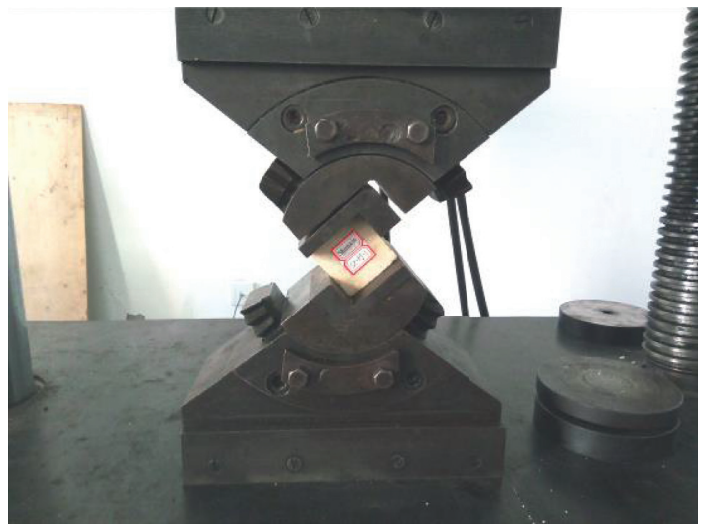

(a)

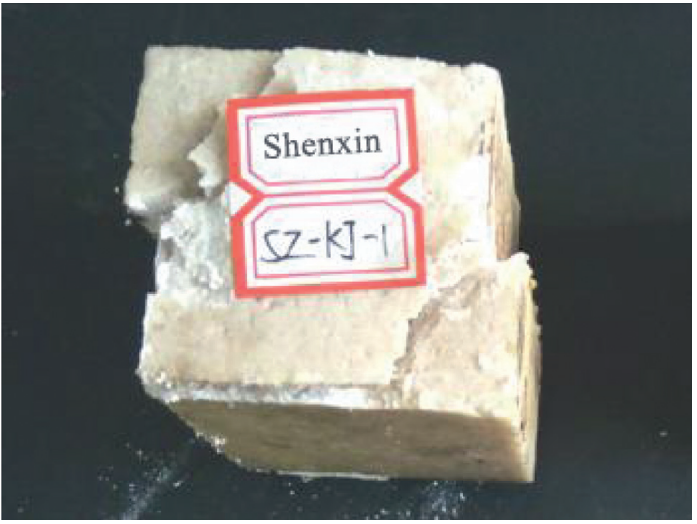

(b)

FIgURE 11: Shear test process and failure specimen. (a) Specimen installation. (b) Shear angle 58 degrees.

result. The range of loose circle in the North Lane of 43 \# coal seam at +575 level is $1600 \mathrm{~mm}-2000 \mathrm{~mm}$. The average is $1775 \mathrm{~mm}$. The length of the bolt meeting the roof fall area of the North roadway in the east wing of the +575 coal seam is at least $2575 \mathrm{~mm}$.

The unreasonable selection of bolt length and the location of bolt end in soft rock are the main contributory factors for roof fall accidents. In order to make the coal mine more safe and efficient for mining, we should carry out the exploration of weak strata. We should reasonably select the length of the anchor rod, ensure the support effect and quality of the anchor rod, and ensure that the detection work and reinforcement support work are carried out simultaneously. At the same time, we should also pay attention to the quality of bolt body and anchoring agent.
3.3. Numerical Simulation Study on the Influence of Working Face Mining on the Mining Roadway. According to the purpose, the numerical calculation model of $+525 \mathrm{~m}$ mining level up to the surface range in the north mining area of the Wudong coal mine is established. This paper analyzes the influence of horizontal stress and vertical stress of +575 coal seam on horizontal mining, and the influence of adjacent coal seam mining on mining roadway.

3.3.1. Influence Analysis of +575 Horizontal Mining in 43\# Coal Seam. The stress distribution of the strike surrounding rock in 43 \# coal seam +575 horizontal working face after mining can be known. The maximum advance stress is $8 \mathrm{~m}$ in front of the working face. In order to analyze the influence 


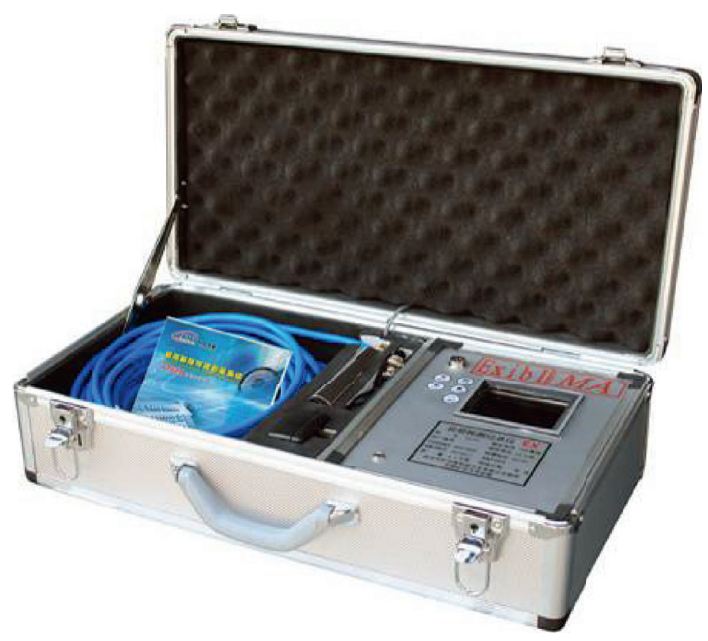

FIGURE 12: YTJ20 type rock exploration recorder.

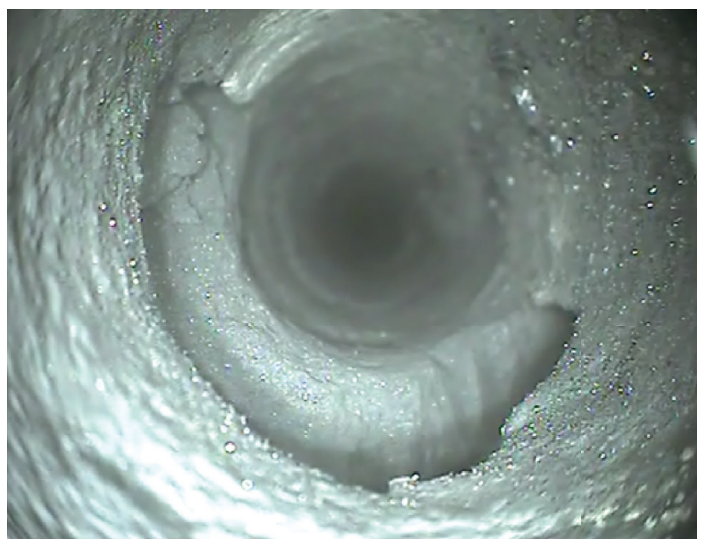

Figure 13: 1\# detection of parallel boreholes in face of coal support.

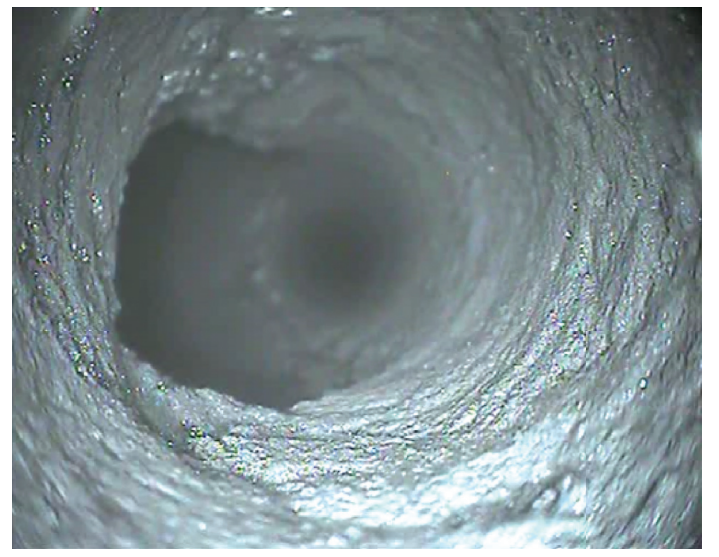

FIgURE 14: 2 \# parallel drilling of coal side of test drilling.

depth of mining face in the floor direction, the vertical stress and horizontal stress data of the floor at $8 \mathrm{~m}$ in front of the working face are extracted when the working face is $100 \mathrm{~m}$.

In order to analyze the influence of upper slice mining on lower slice mining roadway, extract the strike stress data of lower layer +550 horizontal mining roadway. Also, make the vertical stress and horizontal stress distribution curve before and after the working face, as shown in Figures 17 and 18.

It can be seen from Figure 17 that after working face mining, the vertical stress behind the working face (under the goaf) decreases. Formation of pressure relief zone is seen when the working face advances $50 \mathrm{~m}$. The maximum leading vertical stress is $10.9 \mathrm{MPa}$, the peak point is $15 \mathrm{~m}$ away from the coal wall, and the stress concentration factor is 1.6. When the working face advances $100 \mathrm{~m}$, the maximum leading vertical stress is $10.1 \mathrm{MPa}$, the peak point is $15 \mathrm{~m}$ away from the coal wall, and the stress concentration factor is 1.5 . When the working face advances $150 \mathrm{~m}$, the maximum leading vertical stress is $10.7 \mathrm{MPa}$, the peak point is $15 \mathrm{~m}$ away from the coal wall, and the stress concentration factor is 1.6. When the working face advances $200 \mathrm{~m}$, the maximum leading vertical stress is $10.4 \mathrm{MPa}$, the peak point is $15 \mathrm{~m}$ away from the coal wall, and the stress concentration factor is 1.6. It can be seen from the vertical stress distribution curve of the lower-layered roadway after upper-layered mining. After the working face is mined, the leading influence range of the lower slicing roadway is $130 \mathrm{~m}$.

It can be seen from Figure 18 that after working face mining, the horizontal stress behind the working face (under 


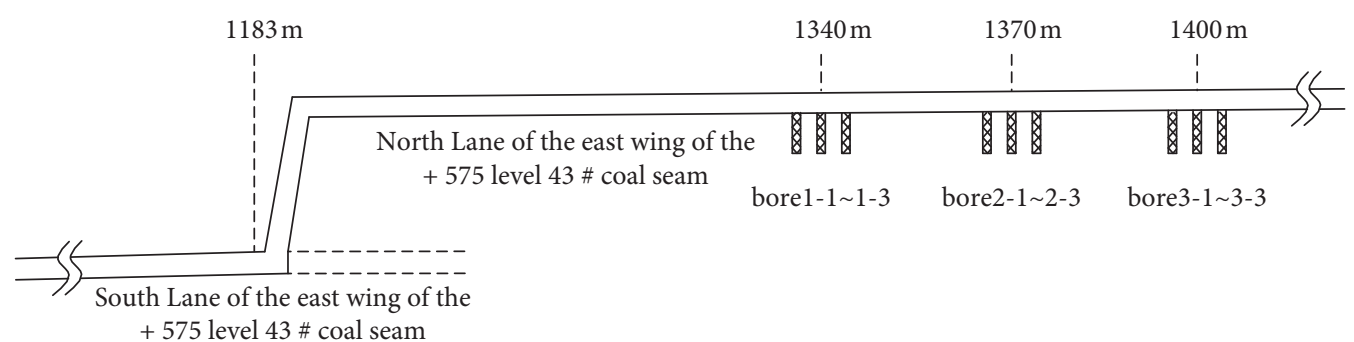

FIgURE 15: Layout of measuring holes in 43 coal seam.

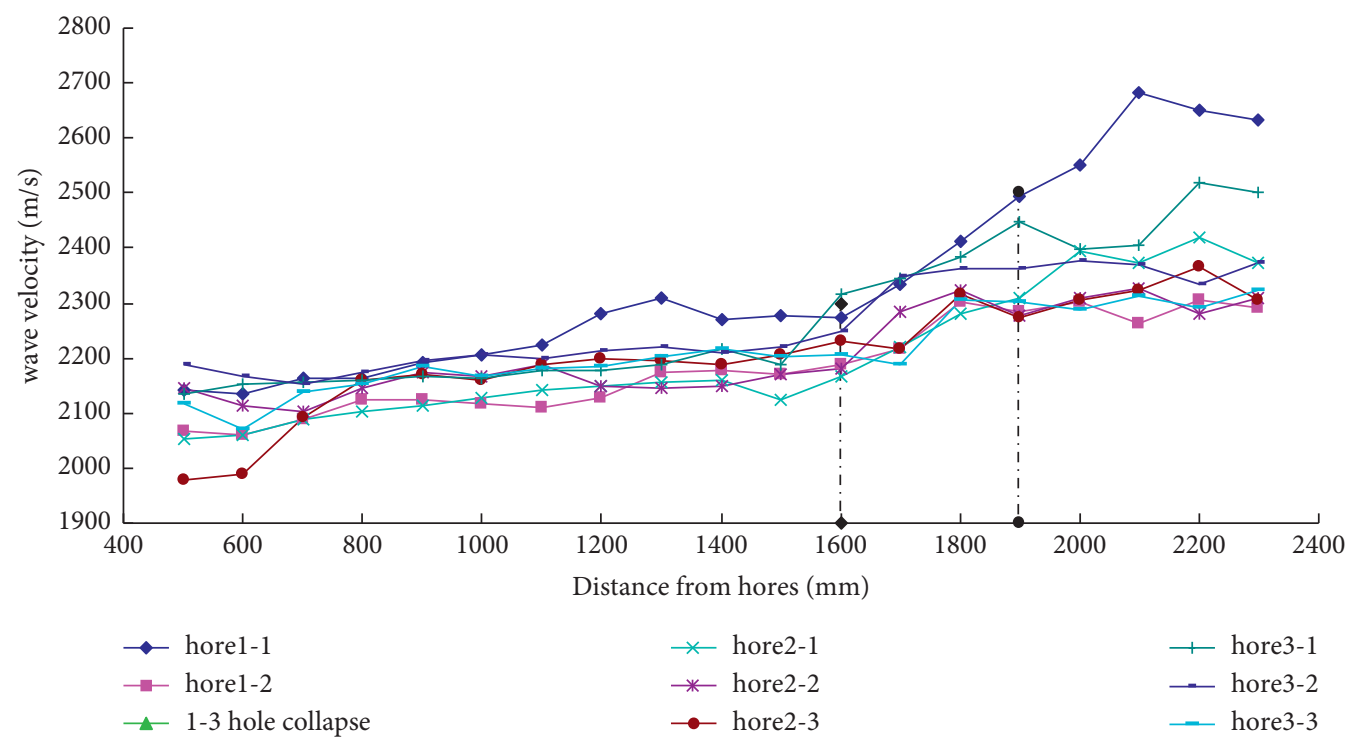

Figure 16: Test curve of surrounding rock loose zone in north roadway of 43 \# coal seam in the east wing of +575 level.

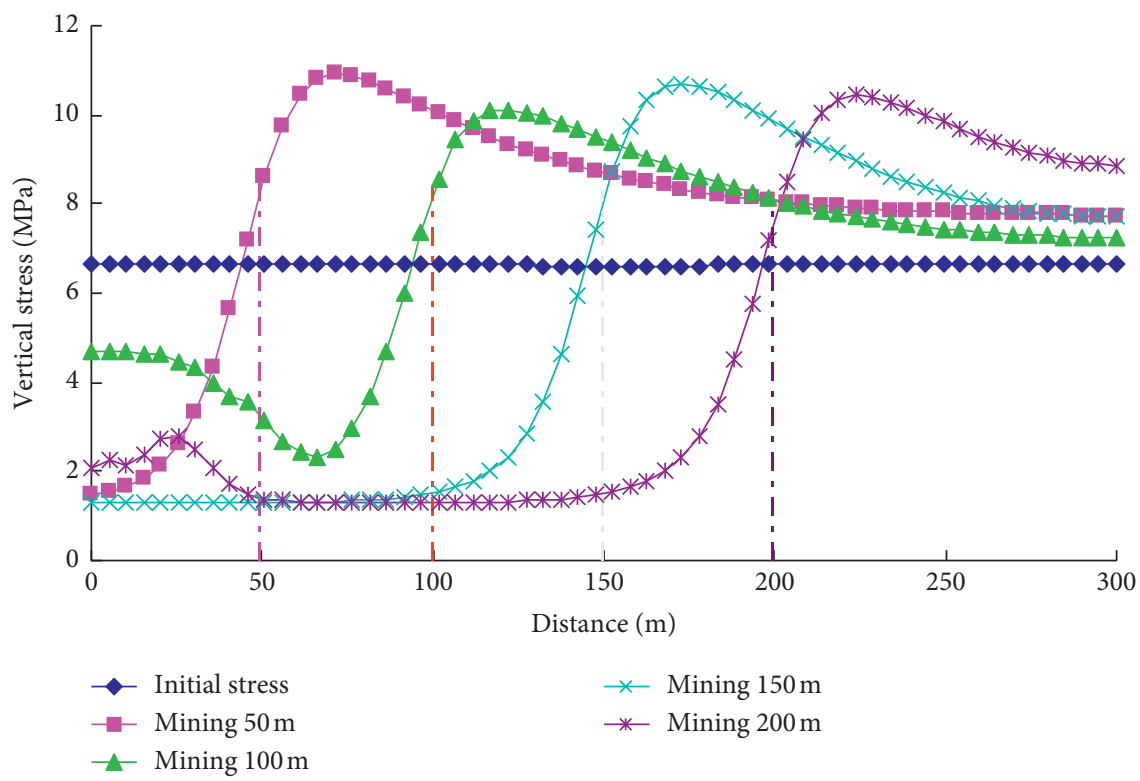

FIGURE 17: Vertical stress distribution of strata strike in roadway of lower slice after upper slice mining.

the goaf) decreases. Formation of pressure relief zone is seen when the working face advances $50 \mathrm{~m}$. The maximum leading horizontal stress is $11.1 \mathrm{MPa}$ and the peak point is
$20 \mathrm{~m}$ away from the coal wall. The stress concentration factor is 1.1. When the working face advances $100 \mathrm{~m}$, the maximum leading horizontal stress is $11.0 \mathrm{MPa}$, the peak point is 


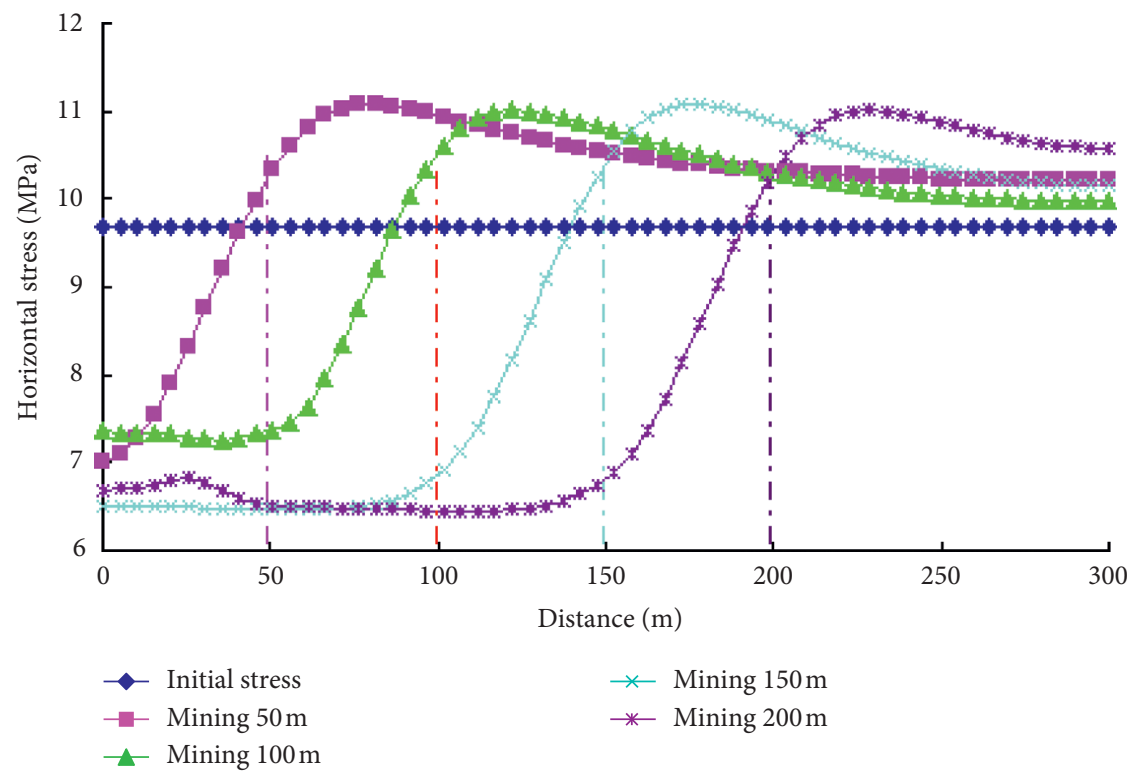

Figure 18: Horizontal stress distribution along the strike of roadway in the lower slice after upper slice mining.

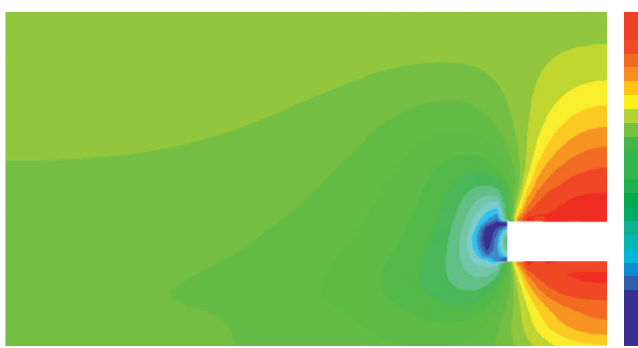

(a)

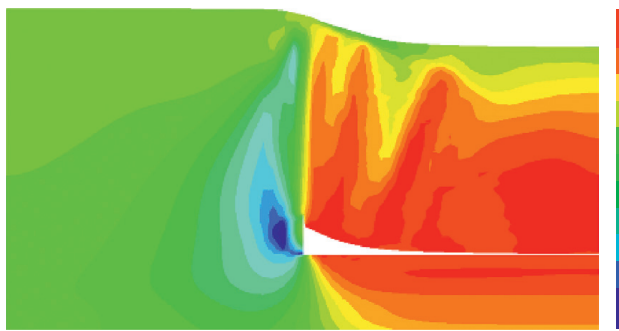

(c)

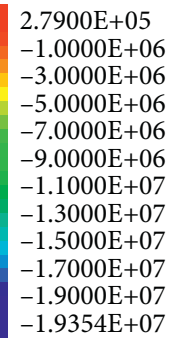

$-1.9354 \mathrm{E}+07$

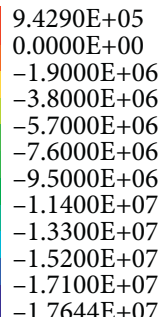

$-1.7644 \mathrm{E}+07$

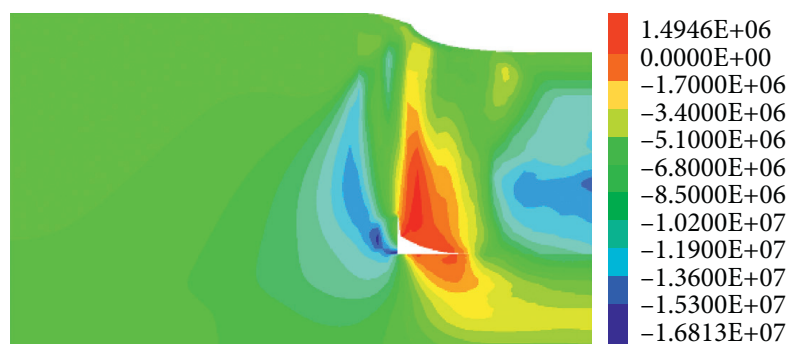

(b)

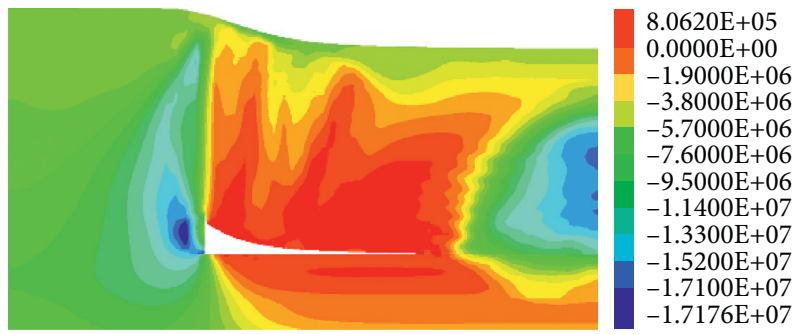

(d)

FIGURE 19: Vertical stress distribution of strike surrounding rock with different advancing distances. (a) Advance $50 \mathrm{~m}$. (b) Advance $100 \mathrm{~m}$. (c) Advance $150 \mathrm{~m}$. (d) Advance $200 \mathrm{~m}$.

$20.0 \mathrm{~m}$ away from the coal wall, and the stress concentration factor is 1.1. When the working face advances $150 \mathrm{~m}$, the maximum leading horizontal stress is $11.1 \mathrm{MPa}$, the peak point is $20 \mathrm{~m}$ away from the coal wall, and the stress concentration factor is 1.1. When the working face advances $200 \mathrm{~m}$, the maximum leading horizontal stress is $11.0 \mathrm{MPa}$, the peak point is $20 \mathrm{~m}$ away from the coal wall, and the stress concentration factor is 1.1. From the distribution curve of horizontal stress in advance, it is seen that after the working face is mined, the leading influence range of the lower slicing roadway is $130 \mathrm{~m}$. Therefore, when driving in the lower layered roadway, the distance between the direction of driving in the upper layered roadway and the direction of driving in the lower layered roadway should be $130 \mathrm{~m}$, and the mine pressure observation and dynamic pressure prevention measures should be strengthened.

3.3.2. Study on the Influence of Working Face Mining on the Mining Roadway. After advancing different distances of +550 level 43 \# coal seam working face in north mining area of the Wudong coal mine, the vertical stress and horizontal stress distribution of the surrounding rock along the coal seam strike are shown in Figures 19 and 20. The advanced 


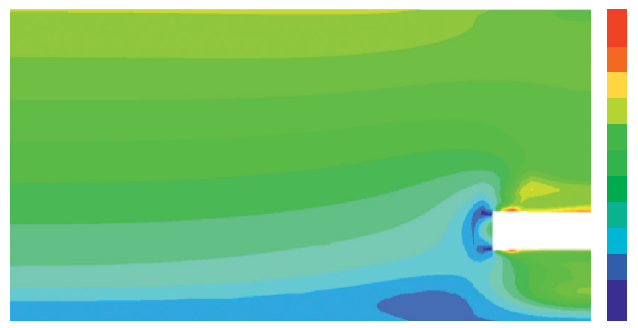

(a)

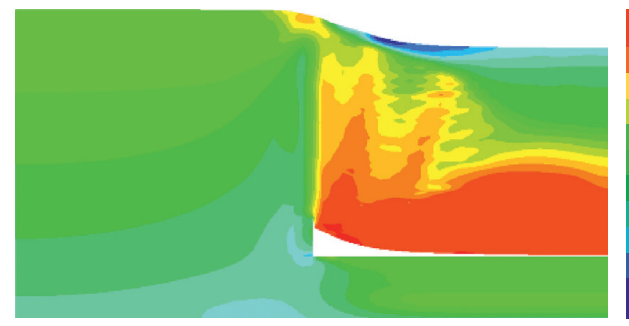

(c)

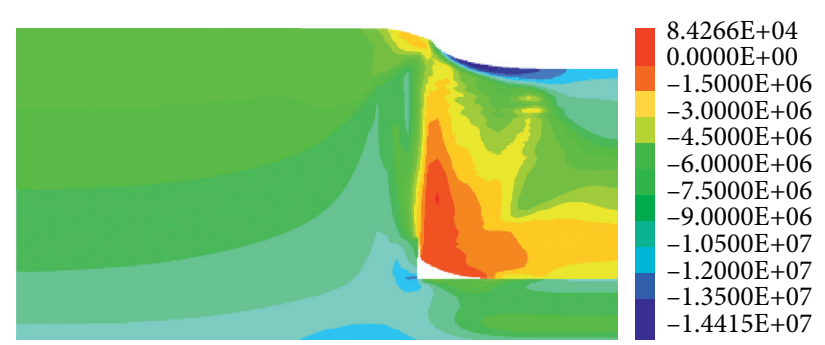

(b)

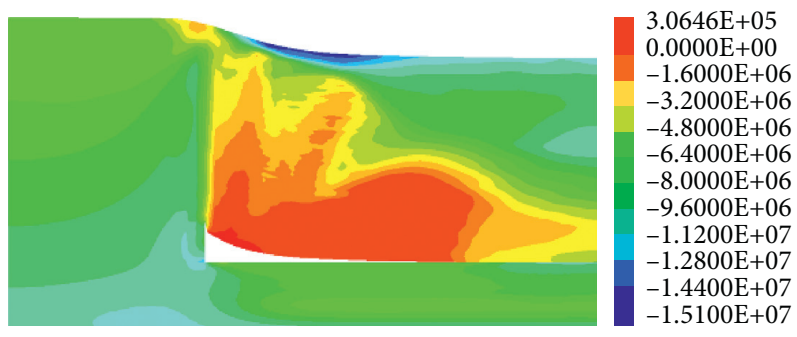

(d)

FIGURE 20: Horizontal stress distribution of strike surrounding rock with different advancing distances. (a) Advance $50 \mathrm{~m}$. (b) Advance $100 \mathrm{~m}$. (c) Advance $150 \mathrm{~m}$. (d) Advance $200 \mathrm{~m}$.

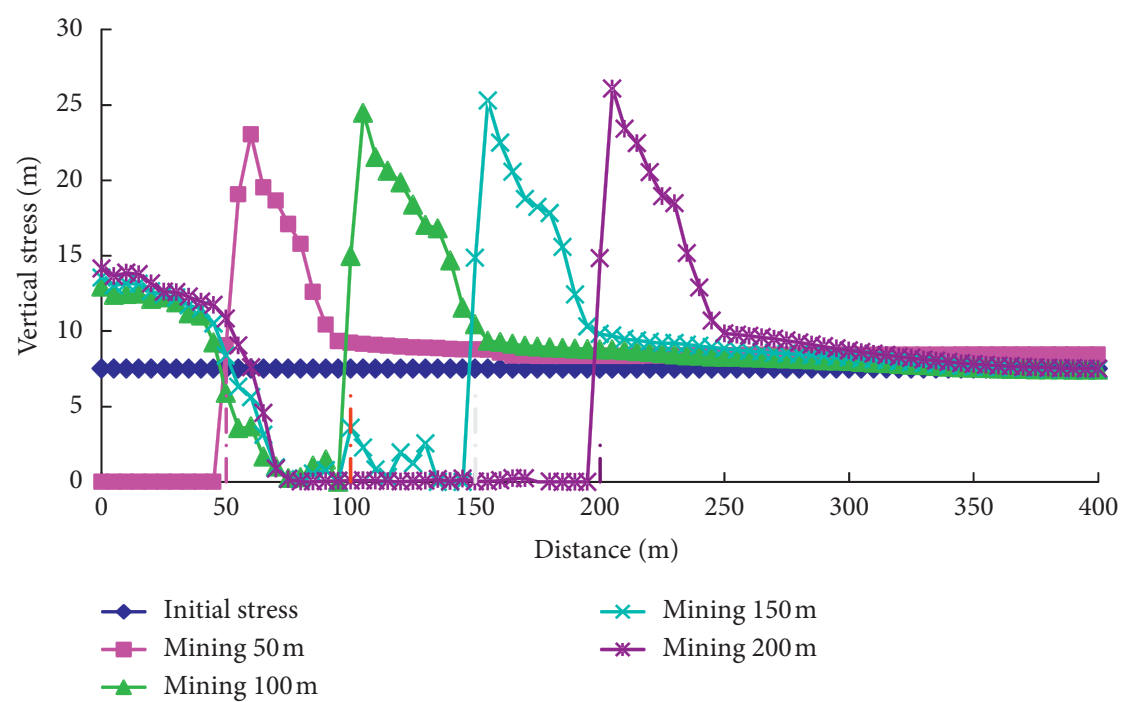

FIGURE 21: Vertical stress distribution of strike after mining in +550 horizontal working face.

vertical stress and horizontal stress curves of working face are shown in Figures 21 and 22.

It can be seen from Figures 19 and 21 that after mining of 43 \# coal seam working face, in front of the working face, the vertical stress concentration is formed in the direction of the roof and floor. The stress concentration in the range of $5 \mathrm{~m}$ to $15 \mathrm{~m}$ in front of the working face is particularly significant. The distribution of high stress area is uniform along the layer height. The high stress area is mainly distributed in the middle and lower part along the stratification height, the roof overburden behind the working face collapses, and the stress reduction area (pressure relief area) is formed in a certain range of the bottom plate. Under the action of broken surrounding rock, the vertical stress increases gradually. The stress reduction zone (pressure relief zone) is formed in a certain range of the bottom plate. At different advancing distances of the working face, the variation range of the maximum vertical stress is small. From the advanced vertical stress curve, the influence range of vertical stress after mining is $90 \mathrm{~m}$.

It can be seen from Figures 20 and 22, after mining of 43 \# coal seam working face, horizontal stress concentration is formed in front of the working face. The stress concentration in the range of $5 \mathrm{~m}$ to $15 \mathrm{~m}$ in front of the working face is 


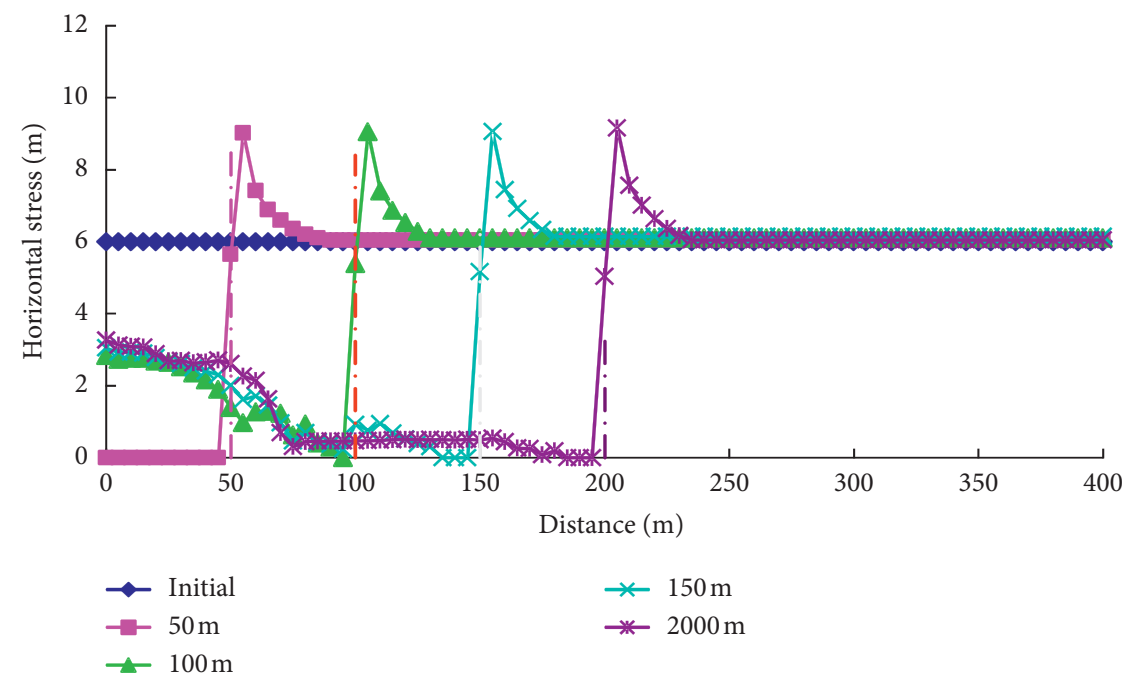

FIgURE 22: Distribution of strike horizontal stress in +550 horizontal working face after mining.

particularly significant, the high stress area is mainly distributed in the middle and lower parts along the delamination height, roof overburden is caving behind the working face, and the stress reduction zone (pressure relief zone) is formed in a certain range of the bottom plate.

At $200 \mathrm{~m}$, the maximum leading horizontal stress is 9.1 $\mathrm{MPa}$, the peak point is $5 \mathrm{~m}$ away from the coal wall, and the stress concentration factor is 1.5. At different advancing distances of the working face, the change range of the maximum value of the leading horizontal stress is small. From the advanced horizontal stress curve, after mining, the leading influence range of horizontal stress is $75 \mathrm{~m}$.

To sum up, it can be seen from the analysis, after working face mining, the maximum value of leading vertical is 26.0 MPa and the stress concentration factor is 3.5. The maximum leading horizontal stress is $9.1 \mathrm{MPa}$ and the stress concentration factor is 1.5. The leading influence distance is $110 \mathrm{~m}$, and the peak point is $5 \mathrm{~m}-10 \mathrm{~m}$ away from the coal wall. Within $45 \mathrm{~m}$ of the advanced working face, the vertical stress concentration factors are greater than 1.5, and the mining roadway of the working face should strengthen the advance support in this range.

\section{Conclusions and Suggestions}

\subsection{Conclusion}

(1) The angle between the maximum principal stress and the strike of mining roadway is nearly vertical in the Wudong coal mine, and mining roadway is strongly affected by in situ stress; it is an important reason for the difficulty of roadway support in the Wudong coal mine.

(2) The drawing experiment of bolt body in the Wudong coal mine shows that the mechanical parameters of the bolt meet the inspection standard. Considering the influence of the strength and elongation of the bar material on the supporting effect, HRB500 thread steel can be used for roadway support in the Wudong coal mine. The anchoring agent has good performance and should be stored in a suitable environment to avoid failure. The length of anchor should be increased or full-length anchorage should be adopted.

(3) The test results of loose ring show that the bolt length of the roadway side in the Wudong coal mine is $2500 \mathrm{~mm}$, the thickness of the loose ring should be less than $1700 \mathrm{~mm}$, and the effective length of the anchor should be larger than the size of the loose circle. The length of the bolt meeting the roof fall area of the North roadway in the east wing of the 43 \# coal seam at +575 level should be at least $2575 \mathrm{~mm}$. It can squeeze and reinforce the broken surrounding rock and improve the supporting effect of roadway surrounding rock.

(4) According to the numerical simulation of north mining area, the vertical stress and horizontal stress of the surrounding rock along the coal seam strike are simulated and analyzed. After mining, the maximum value of advanced vertical is $26.0 \mathrm{MPa}$. The stress concentration factor is 3.5 and the maximum horizontal stress is $9.1 \mathrm{MPa}$. The stress concentration factor is 1.5 and the leading influence distance is $110 \mathrm{~m}$. The peak point is $5 \mathrm{~m}-10 \mathrm{~m}$ away from the coal wall. The vertical stress concentration factor is greater than 1.5 within $45 \mathrm{~m}$ of advanced working face. It is concluded that the working face mining will have a certain impact on the roadway, and the mining roadway of working face should strengthen the advance support in this range.

\subsection{Suggestions}

(1) It is suggested that the length of the bolt should be increased in roadway support in the Wudong coal mine. Full-length anchorage shall be adopted as far as possible to improve the anchoring effect of the 
roadway. It can improve the formula of the anchoring agent, reduce its viscosity, use special installation equipment, reduce the difficulty of manual installation, and improve the installation efficiency.

(2) Under the condition of high stress and steep incline, in the production process of coal mine, with the development of the working face, it is necessary to detect the surrounding coal and rock mass structure and monitor the mine pressure from time to time, and timely adjust and update the support scheme.

\section{Data Availability}

The data used to support the findings of this study are available from the corresponding author upon request.

\section{Conflicts of Interest}

The authors declare that they have no conflicts of interest.

\section{Acknowledgments}

This research was financially supported by the National Natural Science Foundation of China (Grant No. 51904145), Engineering Laboratory of Deep Mine Rockburst Disaster Assessment Open Project (Grant No. LMYK2020006), Liaoning Natural Science Foundation Program Guidance Plan (Grant No. 2019-ZD-0045), Liaoning Provincial Department of Education Project (Grant No. LJ2019JL007), and the State Key Laboratory of Mining Disaster Prevention and Control, Cofounded by Shandong Province and the Ministry of Science and Technology (Grant No. MDPC201806).

\section{References}

[1] H. Rong, H. W. Zhang, and B. Liang, "Instability mechanism of coal rock power system," Acta coalae Sinica, vol. 7, pp. 1663-1671, 2017.

[2] Y. L. Tan, W. Y. Guo, and H. Q. Xin, "Research on key technology of rock burst monitoring in deep mining of coal mine," Acta coalae Sinica, vol. 44, no. 1, pp. 160-172, 2019.

[3] Y. S. Pan, Q. X. Qi, and A. W. Wang, "Theory and technology of three-stage support for roadway with rock burst in coal mine," Acta coalae Sinica, vol. 45, no. 5, pp. 1585-1594, 2020.

[4] L. M. Dou, J. He, and Y. Cao, "Superposition principle of static and dynamic load and its prevention in coal mine," Acta coalae Sinica, vol. 40, no. 7, pp. 1469-1476, 2015.

[5] Y. D. Jiang, Y. S. Pan, and F. X. Jiang, "Mechanism and prevention of rock burst in coal mining in China," Acta coalae Sinica, vol. 39, no. 2, pp. 205-213, 2014.

[6] C. J. Hong, "Research on key technology of surrounding rock control in deep roadway," Journal of China University of mining and technology, vol. 46, no. 5, pp. 970-978, 2017.

[7] F. T. Dong, H. W. Song, Z. H. Guo, S. M. Lu, and S. J. Liang, "Support theory of surrounding rock loose zone in roadway," Acta coalae Sinica, vol. 1, pp. 21-32, 1994.

[8] J. L. Ran, H. S. Wang, and T. C. Li, "Support technology of rectangular Roadway Based on surrounding rock loose circle theory," Coal mine safety, vol. 50, no. 7, pp. 135-139, 2019.
[9] J. F. Pan, "Study on the theory of rock burst starting and its complete set of technology system in coal mine," Acta coalae Sinica, vol. 44, no. 1, pp. 173-182, 2019.

[10] H. Y. Liu, J. P. Zuo, and D. J. Liu, "Optimization of roadway bolt support based on orthogonal matrix analysis," Journal of mining and safety engineering, vol. 38, no. 1, pp. 84-93, 2021.

[11] J. P. Zuo, J. H. Wen, and S. Y. Hu, "Theoretical model and simulation study of equal strength beam support in deep coal mine roadway," Acta coalae Sinica, vol. 43, no. S1, pp. 1-11, 2018.

[12] M. L. Zhang, Y. D. Zhang, and M. Ji, "Optimization of roadway support parameters based on fuzzy extension comprehensive evaluation method," Journal of mining and safety engineering, vol. 33, no. 6, pp. 972-978, 2016.

[13] J. L. Cai, M. Tu, and H. L. Zhang, "Study on deformation instability mechanism and surrounding rock control technology of mining roadway in Jurassic weak cemented soft rock," Journal of mining and safety engineering, vol. 37, no. 6, pp. 1114-1122, 2020.

[14] Y. L. Li, Deformation and Instability Mechanism and Control Technology of Layered Roof in Large Section Coal Roadway of Zhaozhuang Mine, China University of Mining and Technology, Beijing, China, 2017.

[15] Q. B. Meng, L. J. Han, and W. G. Qiao, "Numerical simulation research on Optimization Design of section shape of deep high stress soft rock roadway," Journal of mining and safety engineering, vol. 29, no. 5, pp. 650-656, 2012.

[16] W. M. Wang, X. Gao, and J. D. Jing, "Research on bolt mesh cable coupling support technology in weak cemented soft rock roadway," Coal Science and Technology, vol. 42, no. 1, pp. 23-26, 2014.

[17] Q. X. Huang, Q. Guo, and J. Cao, "Failure mechanism and support technology of soft rock roadway with large deformation," Journal of Xi'an University of Science and Technology, vol. 39, no. 6, pp. 934-941, 2019.

[18] R. S. Yang, Y. Zhu, and Y. L. Li, "Floor Heave Mechanism and control measures of layered floor in weak cemented soft rock roadway," Journal of mining and safety engineering, vol. 37, no. 3, pp. 443-450, 2020.

[19] Y. T. Sun, Study on Rheological Mechanism of Deep Loose Coal Roadway and Control Measures, China University of Mining and Technology, Beijing, China, 2020.

[20] Y. D. Sun, Study on Instability Mechanism and Control of Roadway Surrounding Rock under Dynamic Load of Overburden Fracture in Deep Mining, Liaoning University of Engineering and Technology, Shenyang, China, 2020.

[21] Y. Q. Fan, Y. C. Liu, and M. Z. Zhao, "Distribution law of stress and displacement of surrounding rock in weak cemented soft rock roadway and supporting technology," Coal engineering, vol. 52, no. 4, pp. 84-91, 2020.

[22] L. Chen, Study on Fracture Evolution and Instability Mechanism of Surrounding Rock of Roadway in Steep Coal Seam under the Influence of Mining, China University of Mining and Technology, Beijing, China, 2020.

[23] S. L. Su, X. W. Gu, and L. Zhang, "Physical simulation test research on bearing characteristics of deep layered rock roadway," China mining, vol. 29, no. 1, pp. 123-128, 2020.

[24] Y. Y. Chu, G. F. Ren, and C. Zou, "Study on instability analysis and control method of mine rock contact zone roadway," Journal of Wuhan University (Natural Science Edition), vol. 52, no. 11, pp. 975-980, 2019.

[25] Y. Yu, J. B. Bai, and X. Y. Wang, "Asymmetric deformation and failure characteristics and stability control of soft rock 
roadway," Journal of mining and safety engineering, vol. 31, no. 3, pp. 340-346, 2014.

[26] L. G. Wang, X. X. Miu, J. T. Dong, and X. N. Tan, "Numerical simulation of bolt grouting support in deep soft rock roadway," Geotechnical mechanics, vol. 6, pp. 983-985, 2005.

[27] Y. X. Guo and X. M. Song, "Study on instability mechanism of roof roadway under water drenching in Gob with accumulated water," Coal Science and Technology, vol. 47, no. 11, pp. 36-43, 2019.

[28] Q. L. Yao, X. H. Li, and Q. F. Chen, "Study on instability and failure characteristics and classification of water bearing sandstone roof roadway," Journal of China University of mining and technology, vol. 42, no. 1, pp. 50-56, 2013.

[29] W. X. Zheng, Q. W. Bu, and C. Wang, "Mechanical mechanism of deformation and instability of layered floor in Roadway with equal spacing bottom anchor," Coal mine safety, vol. 50, no. 9, pp. 212-215, 2019.

[30] C. M. Li, G. X. Xie, and Y. D. Lin, "Deformation control mechanism and support practice of surrounding rock with thin layered weak floor in Roadway," Journal of mining and safety engineering, vol. 34, no. 5, pp. 948-954, 2017.

[31] H. F. Lu and D. X. Yao, "Study on stress distribution and failure depth of layered rock mass in mining floor," Journal of rock mechanics and engineering, vol. 33, no. 10, pp. 2030-2039, 2014.

[32] Q. Y. Xu, Q. G. Huang, and G. C. Zhang, "Mechanism and control technology of fracture instability of narrow coal pillar in coal roadway affected by severe mining of fully mechanized top coal caving," Journal of mining and safety engineering, vol. 36, no. 5, pp. 941-948, 2019.

[33] N. Zhang, X. H. Li, and M. S. Gao, "Pre tension support and engineering application of gob side entry driving in mining face," Journal of rock mechanics and engineering, vol. 12, pp. 2100-2105, 2004.

[34] D. Y. Hao, Y. Z. Wu, and H. J. Chen, "Instability mechanism and control of mining roadway in short distance Extra Thick Coal Seam Under Goaf," Journal of coal, vol. 44, no. 9, pp. 2682-2690, 2019.

[35] I. Vazaios, M. S. Diederichs, and N. Vlachopoulos, "Assessment of strain bursting in deep tunnelling by using the finitediscrete element method," Journal of Rock Mechanics and Geotechnical Engineering, vol. 11, no. 1, pp. 12-37, 2019.

[36] L. R. E. Sousa, T. Miranda, R. L. E. Sousa, and J. Tinoco, "The use of data mining techniques in rockburst risk assessment," Engineering, vol. 3, no. 1, pp. 552-558, 2017.

[37] Code of China, GB 50021-2001. Code for Geotechnical Engineering Investigation, Code of China, Ministry of Construction of the People's Republic of China, Beijing, China, 2002. 